\title{
Aspectos da biologia e morfologia de machos da mosca-dos-brotos (Diptera: Lonchaeidae)
}

Biology and morphology of the shoot fly (Diptera: Lonchaeidae).

\author{
Laura Jane Gisloti ${ }^{1 *}$, Angelo Pires do Prado'
}

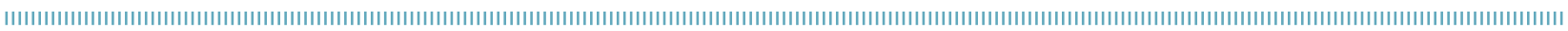

RESUMO: $O$ objetivo deste trabalho foi caracterizar os aspectos biológicos e morfológicos de machos da mosca-dos-brotos Neosilba perezi (Diptera: Lonchaeidae). Em laboratório, o período de incubação dos ovos foi de dois dias, em média, com 55,5\% de viabilidade. Criadas em dieta artificial, à base de farinha de mandioca, o tempo médio de desenvolvimento da larva recém-eclodida até a formação de pupa foi de 15 dias, e o período pupal médio foi de 23 dias. O ciclo biológico (ovo-adulto) foi de aproximadamente 40 dias. Os ovos são de coloração branca, forma elíptica e têm $960 \pm 5,30$ $\mu \mathrm{m}$ de comprimento e $290 \pm 1,30 \mu \mathrm{m}$ de largura na regiấo central; as larvas de aspecto vermiforme, terceiro ínstar, são de coloração branco-leitosa e medem $\pm 10 \mathrm{~mm}$ de comprimento ( $3^{\circ}$ ínstar).

PALAVRAS-CHAVE: ciclo biológico; Neosilba perezi; taxonomia.

\begin{abstract}
The aim of this study was to determine biological and morphological patterns of the male shoot fly, Neosilba perezi (Diptera: Lonchaeidae). Under laboratory conditions, the incubation period of eggs took two days, on average (viability of eggs: $55.5 \%$ ). Bred on an artificial diet, based on cassava flour, the mean time of development of the newly hatched larvae to pupa formation occurred in 15 days, and the average pupal period took 23 days. Finally, the biological cycle, from egg to adult, lasted approximately 40 days. The eggs are white colored, have an elliptical form and are about $960 \pm 5.30 \mu \mathrm{m}$ long and $290 \pm 1.30 \mu \mathrm{m}$ large in the central region; the vermiform larvae, third instar, are milky white and are $\pm 10 \mathrm{~mm}$ long ( $3^{\text {rd }}$ instar).
\end{abstract}

KEYWORDS: biological cycle; Neosilba perezi; taxonomy. 


\section{INTRODUÇÃO}

A família Lonchaeidae compreende um grupo de moscas cujas larvas estâo associadas quase sempre a materiais orgânicos em decomposição. No entanto, o gênero Neosilba tem grande importância na região neotropical, pois suas larvas infestam frutos e hortaliças economicamente importantes (McAlpine; Steyskal, 1982; McAlpine, 1987).

A Neosilba perezi (Romero; Ruppell, 1973) (Diptera, Lonchaeidae) é caracterizada por apresentar larvas que infestam particularmente brotos da mandioca Manihot esculenta Crantz (Euphorbiaceae), sendo conhecida como mosca-dos-brotos, ou mosca-da-mandioca. A fêmea efetua a postura entre folhas da parte apical do broto ou em pequenas cavidades feitas pelo ovipositor, caracterizando a espécie como invasora primária de brotos de mandioca. As larvas perfuram o tecido tenro da planta e matam o ponto de crescimento, podendo assim retardar o desenvolvimento normal das plantas jovens e induzir a emissão de gemas laterais (Bellotti; Schoonhoven, 1978; King; Saunders, 1984; Hogue, 1993).

A mosca-da-mandioca tem origem na regiáo neotropical, sendo citada inicialmente no Brasil nos anos 1940 (Graner, 1942; Zikan, 1944), sendo referida por estes autores como Lonchaea pendula Bezzi, 1919. De fato, a dificuldade taxonômica em distinguir as espécies da família Lonchaeidae se mostra válida também para $N$. perezi, e muitos trabalhos a citam como Silba pendula, (BezzI, 1919); (Brinholi et al., 1974; Bellotti; Kawano, 1980; Oliveira, 1987).

Há registro da ocorrência de $N$. perezi na América do Sul (Bellottr et al., 1999), América Central (Saunders et al., 1998; FHIA, 2003; Capinera, 2004) e sul da América do Norte (Pena; Waddill, 1982; Waddill, 1978 ).

No Brasil, a mosca-da-mandioca é encontrada principalmente na região litorânea e no interior do Estado de São Paulo (Lourençấo et al., 1996; Lorenzi; Dias, 1993; Gisloti; Prado, 2011), no Estado de Minas Gerais (Souza; Reis, 1986) e no sul do Estado da Bahia (Farias et al., 2007; Oliveira et al., 2007), porém, há registros de danos ocasionados pela presença da larva do inseto em culturas de mandioca no Estado do Amazonas (Silva et al., 1981; Magalhâes, 1981), no Estado da Paraíba (Souza et al., 1982), e no Estado de Rondônia (Oliveira, 1987).

Boza; Waddil (1978) estudaram o desenvolvimento de $N$. perezi na Flórida e relataram que o período médio de desenvolvimento de ovo a adulto dura cerca de 40 dias nesta regiấo.

Por haver poucos estudos sobre $N$. perezi, o objetivo deste trabalho foi relatar alguns aspectos da biologia e da morfologia desta espécie.

\section{MATERIAL E MÉTODOS}

No campo experimental do Departamento de Biologia Vegetal da Universidade Estadual de Campinas (UNICAMP)

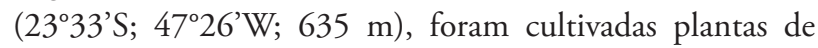
mandioca, as quais foram infestadas naturalmente pela mosca-dos-brotos. Ovos, larvas e adultos da mosca coletados nesta área foram levados para o Laboratório de Entomologia do Departamento de Biologia Animal, no Instituto de Biologia da UNICAMP, para o início deste estudo.

\section{Criação de N. perezi em laboratório}

Adultos (fêmeas e machos) da mosca-dos-brotos obtidos em laboratório foram colocados em gaiolas de plástico de $45 \mathrm{~m}^{3}$, teladas com organza, própria para a criaçâo de moscas. Primeiramente realizou-se a tentativa de criaçáo de $N$. perezi em gaiolas que continham indivíduos machos e fêmeas coletados no campo (descrito anteriormente), alimento e substrato para oviposição. Após um período de seis meses de experimento, verificou-se que não seria possível criar $N$. perezi nessas condiçóes, pois os indivíduos sequer apresentaram indícios de uma possível cópula. Assim, foi necessário desenvolver uma dieta que possibilitasse o desenvolvimento da larva até a formaçáo do adulto da mosca-dos-brotos.

\section{Adequação de dietas artificiais}

Para o desenvolvimento completo dos imaturos, foram avaliados três tipos de dietas à base de farinha de mandioca: dieta $1(\mathrm{~d} 1)-10 \mathrm{~g}$ de farinha de mandioca e $30 \mathrm{~mL}$ de água; dieta $2(\mathrm{~d} 2)-20 \mathrm{~g}$ de levedura de cerveja, $20 \mathrm{~g}$ de leite em pó, $5 \mathrm{~g}$ de caseína e $15 \mathrm{~g}$ de ágar; e dieta 3 (d3) $10 \mathrm{~g}$ de farinha de mandioca, $50 \mathrm{~g}$ de levedura de cerveja e $30 \mathrm{~mL}$ de água.

O preparo das dietas consistiu na mistura dos componentes de cada dieta até a completa homogeneização em liquidificador, exceto o agar da dieta 2 (d2), que foi preparado com $310 \mathrm{~mL}$ de água aquecida a uma temperatura próxima da fervura. Em seguida, o agar preparado foi misturado aos demais componentes, e o meio foi homogeneizado. Cada dieta foi utilizada 30 minutos após o preparo. Com unidade experimental, foram usadas 100 larvas recém-eclodidas; estas foram mantidas em placas de vidro com a dieta, sendo mantida a proporção de $2 \mathrm{~g}$ de dieta para cada larva. As placas de vidro foram conservadas em condiçóes controladas de $23 \pm 1^{\circ} \mathrm{C}$, UR $=60 \%$ e fotofase de 12 horas durante todo o experimento.

A dieta que proporcionou maior velocidade de desenvolvimento e maior viabilidade das pupas foi definida como a ideal para o desenvolvimento vital de $N$. perezi em laboratório. 


\section{Biologia de N. perezi mantida em dieta artificial}

Em campo, foram coletados 100 ovos de $N$. perezi de brotos de mandioca no período de março a agosto de 2008. Os brotos foram coletados e acondicionados em sacos de papel e levados ao laboratório.

Os ovos foram retirados dos brotos de mandioca e isolados em placas de vidro, com papel filtro umedecido ao fundo, e mantidos em câmara climatizada do tipo B.O.D. sob condiçóes controladas $\left(22 \pm 1^{\circ} \mathrm{C} ; 70 \pm 10 \%\right.$ e 12 horas de fotofase). As larvas recém-eclodidas de $N$. perezi foram transferidas para placas com a dieta definida como ideal para seu desenvolvimento e mantidas em B.O.D nas mesmas condições citadas anteriormente, até que houvesse formação de pupa. As pupas foram transferidas para caixas plásticas vedadas com organza $(25 \times 50 \times 10 \mathrm{~cm})$, contendo areia fina umedecida e autoclavada $( \pm 2 \mathrm{~cm})$ como substrato até que os adultos emergissem.

A umidade foi vistoriada diariamente e os adultos emergidos foram coletados. Determinaram-se o período médio de eclosão da larva 1 ( \pm Erro Padrão - EP), o período médio larval ( $\pm \mathrm{EP})$, o período médio pupal $( \pm \mathrm{EP})$, além de estimarem-se a viabilidade dos ovos (\% dos ovos que geraram larvas), a viabilidade das larvas (\% das larvas que puparam) e a viabilidade pupal (\% das pupas que originaram adultos).

\section{Morfologia de N. perezi}

a. Imaturos: para o estudo da morfologia e dos parâmetros morfométricos, 20 exemplares de terceiro ínstar e 20 ovos foram fixados em álcool etílico 70\%. Indivíduos vivos foram observados para a descrição do padrão de coloração das larvas. A terminologia adotada para as descriçóes dos ovos e das larvas foi baseada em McAlpine (1987). Utilizaram-se o microscópio ótico Zeiss Axiolplan e o programa computacional Leica IM50 para Windows XP, os quais foram responsáveis pela obtenção de imagens e medidas, respectivamente. As medidas apresentadas correspondem à média \pm EP em milímetros. Para os ovos, foram realizadas mediçôes de altura e largura. Para as larvas, foram medidos o esqueleto cefalofaringeano e os espiráculos posteriores. Assim, elas foram dissecadas de forma que primeiro e o último segmento foram destacados a fim de facilitar a observaçáo dessas estruturas.

Os parâmetros utilizados na morfometria das estruturas anteriores e posteriores das larvas foram: 1) altura dos espiráculos posteriores em vista lateral; 2) largura dos espiráculos posteriores em vista lateral; 3) diâmetro do espiráculo posterior direito em vista dorsal; 4) distância entre os espiráculos posteriores em vista dorsal; 5) altura da base da mandíbula em vista lateral; 6) comprimento angular da mandíbula em vista lateral (Figs. 1, 2 e 3).

b. Genitália e nervuras das asas direita dos machos: essas estruturas são utilizadas na caracterização das espécies do gênero Neosilba.

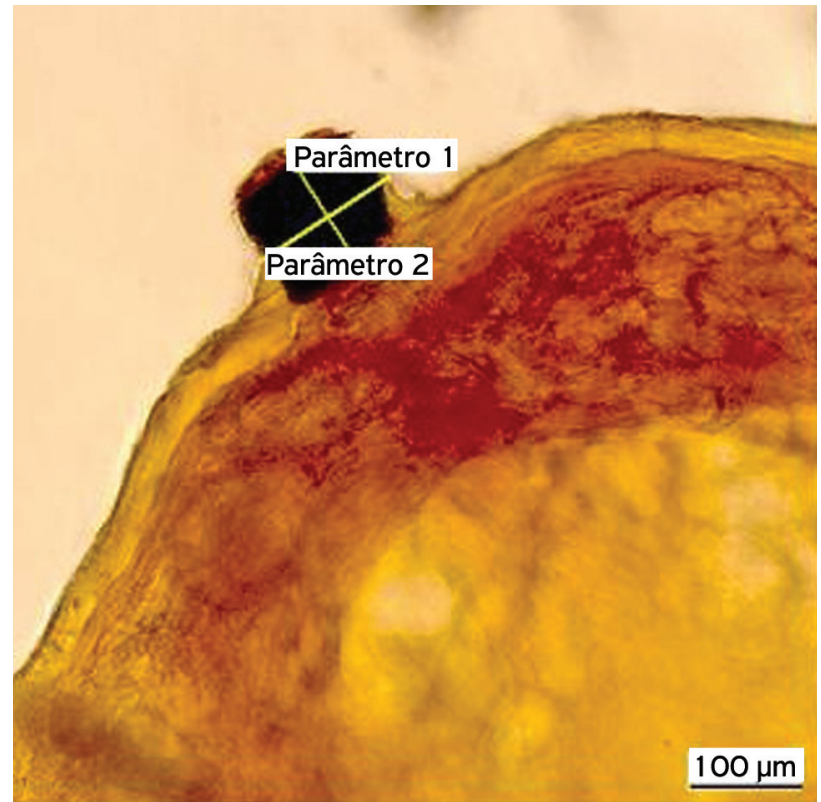

Figura 1. Parâmetros utilizados na morfometria das estruturas anteriores e posteriores das larvas de Neosilba perezi: 1. Altura dos espiráculos posteriores em vista lateral, 2. Largura dos espiráculos posteriores em vista lateral.

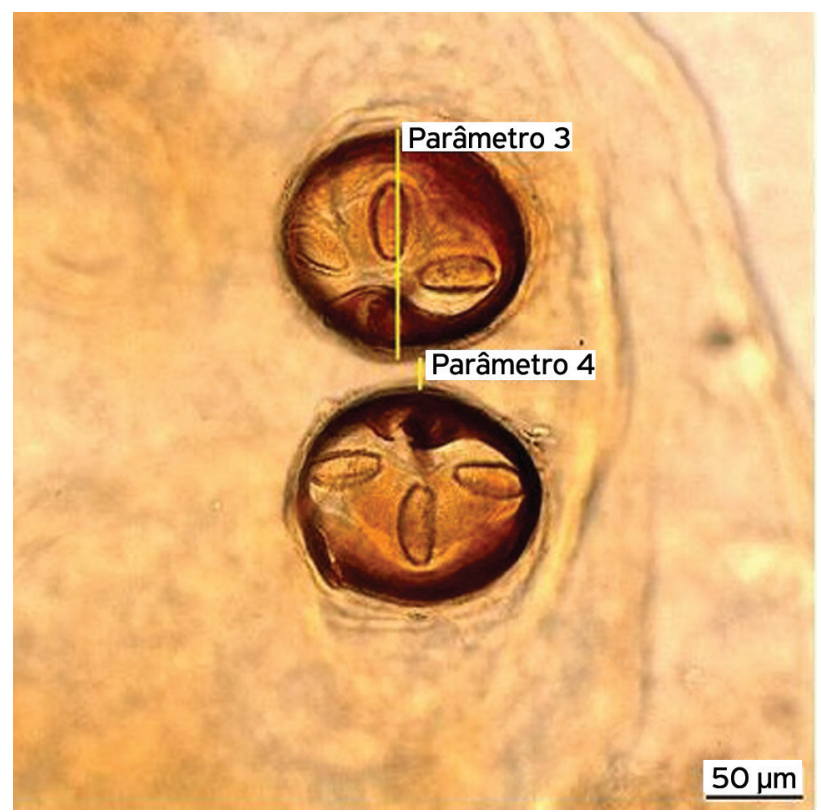

Figura 2. Parâmetros utilizados na morfometria das estruturas anteriores e posteriores das larvas de Neosilba perezi: 3. Diâmetro do espiráculo posterior direito em vista dorsal; 4. Distância entre os espiráculos posteriores em vista dorsal.

$\mathrm{Na}$ análise descritiva da genitália, os machos $(\mathrm{n}=30)$ foram clarificados em $\mathrm{KOH} 10 \%$ durante 24 horas e individualizados em frascos contendo álcool $70 \%$. Com o auxílio de um microscópio estereoscópico, as genitálias foram dissecadas e montadas em lâmina e lamínula para a descrição de suas características. As estruturas foram fotografadas utilizando os recursos citados. As ilustraçôes foram elaboradas com o auxílio de câmara clara acoplada ao microscópio ótico. Após finalização com caneta nanquim descartável, as ilustraçóes foram digitalizadas. 
As asas dos espécimes (asa direita, $\mathrm{n}=20$, machos) foram retiradas, de igual modo, sob microscópio estereoscópico em uma placa de Petri contendo álcool 70\%. Em seguida, foram fixadas em uma lâmina e lamínula nas quais foram fotografadas com o auxílio do mesmo microscópio e programa computacional. A morfometria das nervuras costais (média \pm EP) foi realizada a partir de cinco medidas externas: 1) da parte externa da nervura umeral (h) até a nervura subcostal (Sc); 2) da nervura subcostal (Sc) até a parte externa da nervura Radial 2 (R2); 3) da nervura Radial 2 (R2) até a parte externa da Radial 3 (R3); 4) deste último ponto (R3) até a parte inferior anterior da nervura média (MA); e 5) nervura que se localiza entre a célula Dm e CuAl (Fig. 4).

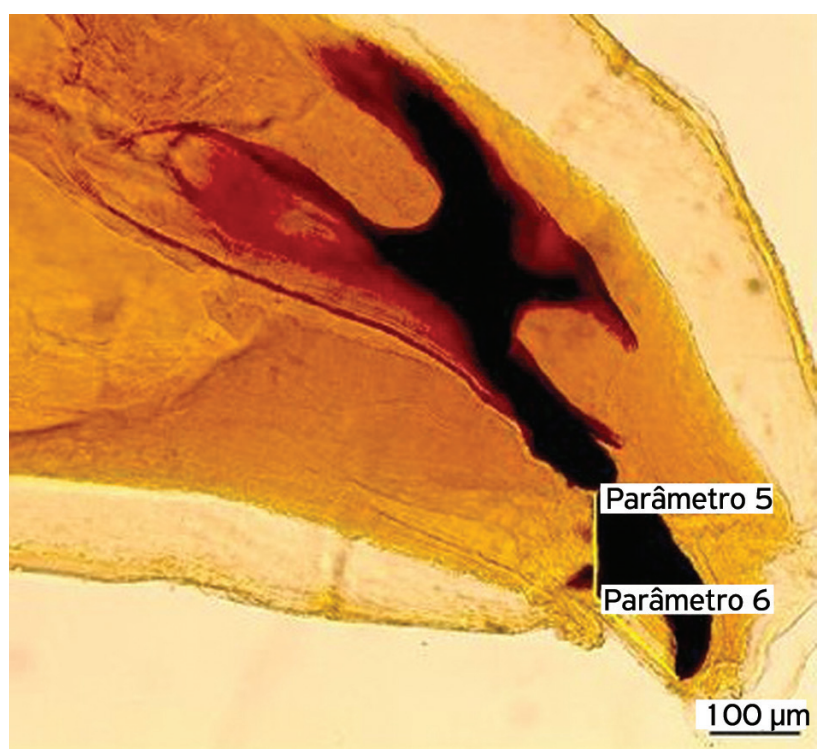

Figura 3. Parâmetros utilizados na morfometria das estruturas anteriores e posteriores das larvas de Neosilba perezi: 5. Altura da base da mandíbula em vista lateral; 6. Comprimento angular da mandíbula em vista lateral.

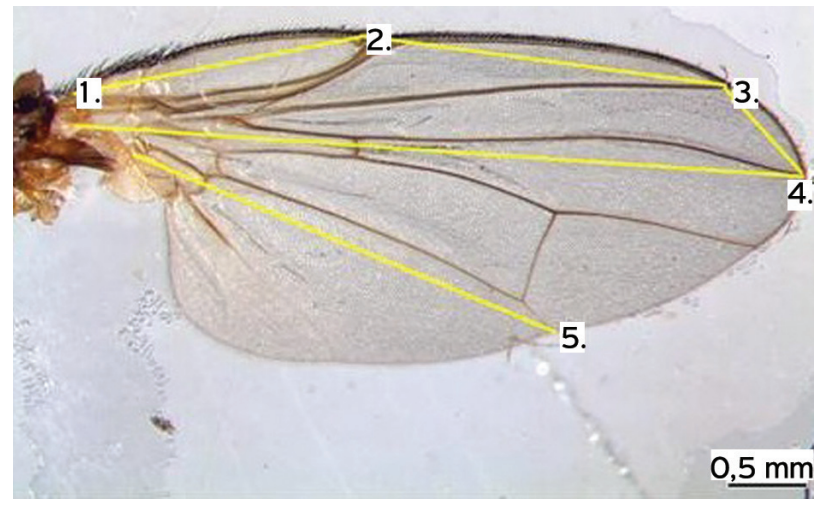

Figura 4. Pontos utilizados na morfometria alar de Neosilba perezi: 1) da parte externa da nervura umeral ( $h$ ) até nervura subcostal (Sc); 2) da nervura subcostal (Sc) até a parte externa da nervura Radial 2 (R2); 3) da nervura Radial 2 (R2) até a parte externa da Radial 3 (R3); 4) deste último ponto (R3) até a parte inferior anterior da nervura média (MA); e 5) nervura que se localiza entre a célula Dm e CuAl.
A terminologia utilizada para descrever a genitália de $N$. perezi segue McAlpine (1989) e os espécimes-testemunho do trabalho estáo depositados no Departamento de Biologia Animal, na UNICAMP.

\section{RESULTADOS E DISCUSSÃO}

\section{Criação de $\mathbf{N}$. perezi em laboratório}

McAlpine (1961) verificou que, para moscas desta família, o enxameamento é comum para que haja cópula, e este pode ter sido o fator que dificultou a criação deste inseto em cativeiro. Desta forma, o estudo da biologia de $N$. perezi foi somente possível devido à manutenção dos insetos em dieta artificial, a qual possibilitou o desenvolvimento desta mosca e o registro de dados biológicos desta espécie.

\section{Adequação de dietas artificiais}

Há registro de alguns estudos sobre o desenvolvimento e a adequaçáo de dietas artificiais para a criação de moscas da superfamília Tephritoidea. Contudo, a grande maioria desses trabalhos foi elaborada visando à criação de espécies consideradas importantes pragas para a fruticultura (Zucoloto et al., 1979; JaLdo et al. 2001; Sobrinho et al., 2006). No entanto, ainda não tinha sido estabelecida uma dieta que possibilitasse a criação de moscas da família Lonchaeidae até o presente momento.

A farinha de mandioca como fonte nutricional para as larvas de $N$. perezi foi utilizada por ser um nutriente similar ao recurso alimentar natural (REINECKE, 1985) e se mostrou bastante interessante, já que possibilitou o desenvolvimento completo da mosca.

Mesmo que $N$. perezi tenha completado o ciclo biológico nas três dietas, a $\mathrm{d} 3$ foi a mais adequada para seu desenvolvimento, propiciando maior velocidade de desenvolvimento (média 38 dias), menor mortalidade das larvas de primeiro ínstar (24\%) e maior viabilidade das pupas (63\%, em média). Na dieta 1 (d1) ocorreu uma alta taxa de mortalidade das larvas de primeiro ínstar (52\%) e baixa viabilidade das pupas (20\%), e na dieta $2(\mathrm{~d} 2)$ ocorreu a menor viabilidade pupal (12\%), além de apresentar o maior período de desenvolvimento (média de 44 dias) (Tabela 1). Esses resultados indicaram que a dieta 3 (composta por farinha de mandioca, água e levedura de cerveja) pode ser utilizada na criaçáo de $N$. perezi em laboratório.

\section{Biologia de N. perezi mantida em dieta artificial}

Um total de 102 ovos foi coletado, dos quais eclodiram 57 larvas de primeiro ínstar. Estas, por sua vez, originaram 38 pupas, as quais deram origem a 23 adultos (13 machos 
e 10 fêmeas). A viabilidade dos ovos foi de 55,8\%; a viabilidade das larvas, de 66,6\%; a viabilidade das pupas, de $60,5 \%$; e a viabilidade de ovo a adulto, de $22,5 \%$. A duração média do desenvolvimento de $N$. perezi, de ovo a adulto, foi de 41 dias (39 a 43), sendo o período médio de eclosão da larva igual a 2 dias $\pm 0,2$ (um a quatro); o tempo médio entre a larva de primeiro ínstar e a pupa foi de $15 \pm 0,13$ dias ( 12 a 18 ), e o período médio de pupa a adulto foi de $23 \pm 0,35$ dias ( 21 a 26) (Tabela 2). O período completo de desenvolvimento de ovo a adulto foi bastante similar àquele encontrado por WADDILL (1978) e Boza; Waddill (1978) (Tabela 2).

\section{Morfologia de N. perezi}

a. Os ovos $N$. perezi são bastante similares a algumas espécies da família Tephritidae, sendo comumente menores do que Anastrepha spp. (Lawrence, 1979; Steck; Wharton, 1988; Carroll; Wharton, 1989; Selivon; Perondini, 1999). Possuem coloração branca e são depositados isoladamente ou em grupos, em número de até quatro, firmemente aderidos ao substrato. Apresentam contorno elíptico com aproximadamente $960 \pm 5,30 \mu \mathrm{m}$ de comprimento e $290 \pm 1,30 \mu \mathrm{m}$ de largura na regiáo central. O índice do ovo (a razão entre o comprimento e a largura) foi calculado utilizando-se a largura da região central, e o valor obtido foi 3,31. O revestimento externo dos ovos apresenta o exocório extremamente regular, sendo que a maioria das células do exocório possui ornamentação de aspecto hexagonal e, algumas vezes, pentagonal (Figs. 5 e 6 ).

Tabela 1. Mortalidade de larvas de primeiro ínstar, viabilidade das pupas e tempo de desenvolvimento de larvas recémeclodidas de Neosilba perezi, submetidas a três dietas.

\begin{tabular}{lccc} 
& D1 & D2 & D3 \\
Mortalidade L1 & $52 \%$ & $46 \%$ & $24 \%$ \\
\hline Viabilidade pupal & $20 \%$ & $12 \%$ & $63 \%$ \\
\hline Tempo de desenvolvimento (dias) & 41 & 44 & 38 \\
\hline
\end{tabular}

D1: farinha de mandioca e áqua, D2: levedura de cerveja, leite em pó, caseína e agar e D3: farinha de mandioca, água e levedura de cerveja.

Tabela 2. Duração em dias (média \pm erro padrão) das fases de desenvolvimento de Neosilba perezi a $22 \pm 1{ }^{\circ} \mathrm{C}, 70 \pm 10 \%$ de UR e 12 horas de fotofase.

\begin{tabular}{lrcc}
$\begin{array}{l}\text { Estágio de } \\
\text { N. perezi }\end{array}$ & $\mathbf{n}$ & Média \pm EP & $\begin{array}{c}\text { Viabilidade } \\
(\%)\end{array}$ \\
\hline Ovo & 102 & $2,0 \pm 0,26(1-4)^{1}$ & 55,8 \\
\hline Larval & 57 & $15,8 \pm 0,13(12-18)$ & 66,6 \\
\hline Pupal & 38 & $23,3 \pm 0,35(21-26)$ & 60,5 \\
\hline Ovo-Adulto & 23 & $41,4 \pm(39-43)$ & 22,5 \\
\hline
\end{tabular}

'Intervalo de Variação; EP: erro padrão.
As larvas de terceiro ínstar de $N$. perezi medem cerca de $10 \mathrm{~mm}$ de comprimento, apresentando coloração de branco leitosa a creme. São vermiformes, acefálicas e apresentam partes bucais que consistem de ganchos orais curvados na região anterior, associados a escleritos internos. $\mathrm{O}$ esqueleto céfalo-faríngeo é fortemente esclerotizado, e o esclerito intermediário apresenta-se delgado quando visto de perfil e em forma de 'H' quando visto ventralmente. A maxila é curva, robusta e totalmente esclerotizada, e a base se apresenta alargada, afinando-se em direção à região anterior, a qual se mostra pontiaguda (Fig. 3). A estrutura esclerotizada do esqueleto cefalofaringeano é extremamente importante, já que

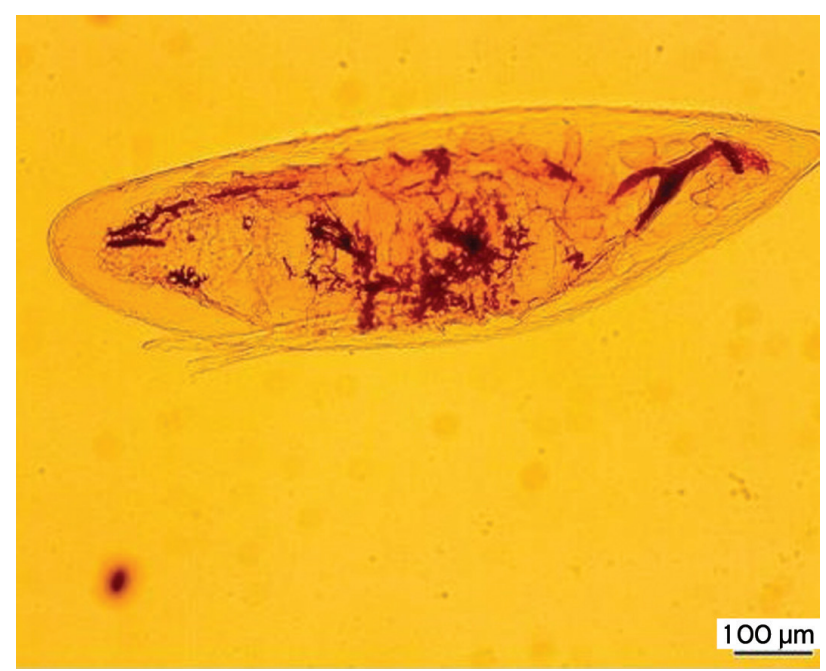

Figura 5. Morfologia do ovo de Neosilba perezi em vista ao microscópio ótico.

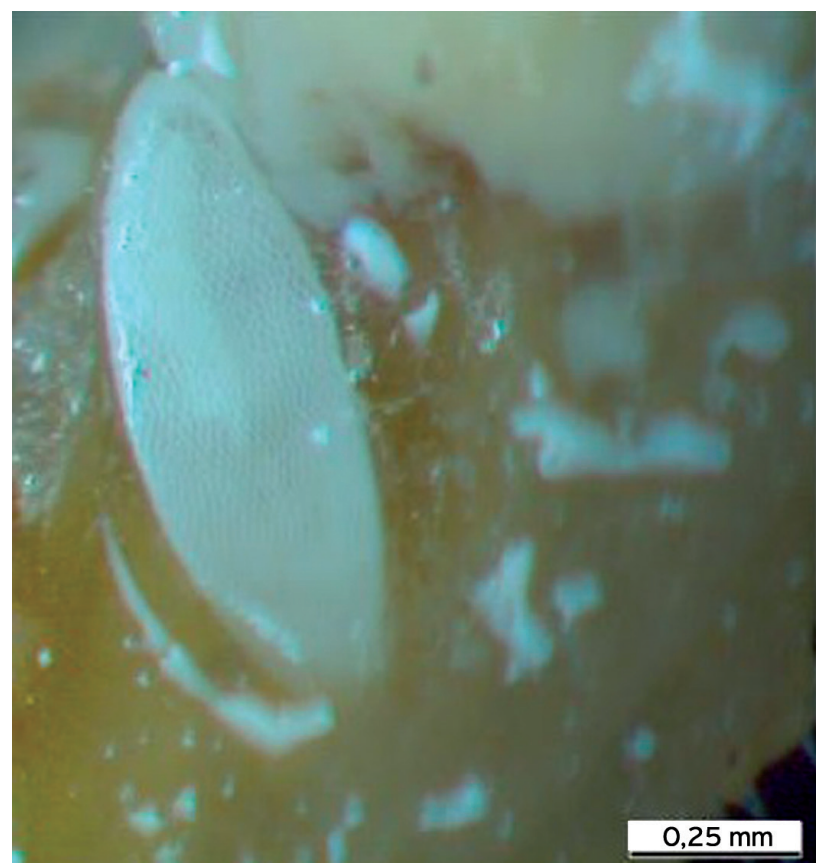

Figura 6. Morfologia do ovo de Neosilba perezi em vista ao microscópio estereoscópio. 
Tabela 3. Medidas (média \pm erro padrão) de parâmetros das mandíbulas e de espiráculos posteriores de larvas Neosilba perezi.

\begin{tabular}{cc} 
Parâmetros $(\mu \mathrm{m})$ & Média \pm EP \\
\hline 1 & $118,1 \pm 0,77(116,3-119,0)^{1}$ \\
\hline 2 & $137,3 \pm 2,23(132,4-139,8)$ \\
\hline 3 & $135,9 \pm 0,94(135,4-137,4)$ \\
\hline 4 & $94,1 \pm 1,39(92,7-96,7)$ \\
\hline 5 & $121,5 \pm 1,49(118,7-123,7)$ \\
\hline 6 & $94,3 \pm 1,75(92,7-97,2)$ \\
\hline
\end{tabular}

'Intervalo de Variação. 1: altura dos espiráculos posteriores em vista lateral; 2: largura dos espiráculos posteriores em vista lateral; 3: diâmetro do espiráculo posterior direito em vista dorsal; 4: distância entre os espiráculos posteriores em vista dorsal; 5: altura da base da mandíbula em vista lateral; 6: comprimento angular da mandíbula em vista lateral. $(n=20)$; EP: erro padrão.

A
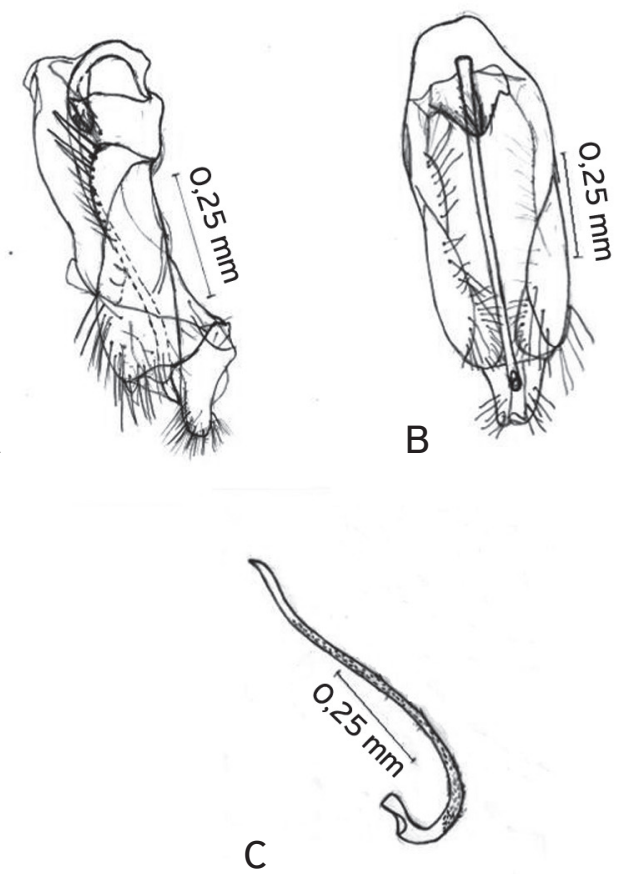

Figura7. (A) Terminália genital masculina de Neosilba perezi em vista lateral (176X). (B) Terminália genital masculina de Neosilba perezi em vista ventral (176X). (C) Edeago de Neosilba perezi em vista lateral (176X).

Tabela 4. Média ( \pm erro padrão) das medidas das nervuras das asas de machos de Neosilba perezi em milímetros.

\begin{tabular}{cc} 
Medidas (mm) & Média \pm EP \\
\hline 1) $\mathrm{h}-\mathrm{Sc}$ & $1,2 \pm 0,02(1,0-1,4)^{1}$ \\
\hline 2) $\mathrm{Sc}-\mathrm{R} 2$ & $2,0 \pm 0,02(1,8-2,1)$ \\
\hline 3) $\mathrm{R} 2-\mathrm{R} 3$ & $0,6 \pm 0,00(0,6-0,6)$ \\
\hline 4) $\mathrm{R} 3-\mathrm{MA}$ & $3,6 \pm 0,03(3,3-3,7)$ \\
\hline 5) $\mathrm{Dm}-\mathrm{CuAl}$ & $2,0 \pm 0,01(1,9-2,0)$ \\
\hline
\end{tabular}

'Intervalo de Variação. 1) da parte externa da nervura umeral (h) até nervura subcostal (Sc); 2 ) da nervura subcostal (Sc) até a parte externa da nervura Radial 2 (R2); 3) da nervura Radial 2 (R2) até a parte externa da Radial 3 (R3); 4) deste último ponto (R3) até a parte inferior anterior da nervura média (MA); e 5) nervura que se localiza entre a célula Dm e CuAl. $(n=20)$; EP: erro padrão. as fêmeas de $N$. perezi depositam os ovos externamente ao tecido da planta, e a larva eclodida deve penetrar ativamente no broto de mandioca (BozA; WADDILL, 1978).

Os espiráculos posteriores estão localizados no último segmento abdominal, póstero-dorsalmente, e mostram-se esclerotizados com o peritrema circundando as fendas espiraculares em número de três (Fig. 2). Considera-se que a estrutura morfológica dos espiráculos posteriores de $N$. perezi poderá ser utilizada na caracterização da espécie, assim como proposto por Krivosheina (2005). As medidas das mandíbulas e de espiráculos posteriores de larvas $N$. perezi obtidas estão representadas na Tabela 3 .

b. Genitália e nervuras das asas direita dos machos: essas estruturas são utilizadas na caracterização das espécies do gênero Neosilba.

O epândrio se mostra ereto ao longo da margem ventral, sendo mais comprido do que largo e apresentando pelos longos que se alongam mais ao final da genitália. Os surstilos se mostram mais espaçados anteriormente (Figs. 7A e 7B). O filamento do edeago se apresenta ligeiramente robusto e longo com inúmeras setas ao longo de todo o comprimento (Fig. 7C). A genitália masculina de $N$. perezi é semelhante à de Neosilba nigrocaerulea (Malloch, 1920) (McAlpine; Steyskal, 1982), porém, as duas espécies podem ser diferenciadas através da observação da disposição dos surstilos e do edeago de $N$. perezi, o qual apresenta as inúmeras setas (Fig. 7C).

A morfometria nas nervuras alares tem demonstrado ser uma ferramenta bastante útil na caracterização taxonômica de espécies de Diptera (CARsola; AÑez, 1988; Marcondes, 1997; Araújo; Zucchi, 1998). As medidas (média) de nervuras das asas dos machos de $N$. perezi estão representadas na Tabela 4 .

Devido à escassez de taxonomistas de Lonchaeidae, já que o treinamento deve ser especializado para a identificação correta das espécies (DE ConTi et al., 1984), novas informações de parâmetros utilizados na caracterização de espécies do gênero Neosilba são muito importantes.

\section{CONCLUSÕES}

A utilização de uma dieta à base de farinha de mandioca e levedura de cerveja propicia a criação de $N$. perezi em laboratório. O ciclo de vida de ovo a adulto de $N$. perezi dura cerca de 40 dias, e o período de desenvolvimento de larva de primeiro ínstar à formação da pupa é de aproximadamente 20 dias. O período de incubação é de dois dias, e o período pupal dura 23 dias. 


\section{REFERÊNCIAS}

ARAÚJO, E.L.; ZUCCHI, R.A. Utilização da análise discriminante em estudos taxonômicos de moscas-das-frutas do gênero Anastrepha Schiner, (Diptera: Tephritidae). Scientia agrícola, v.55, n. 1, p.105-111, 1998.

BELLOTTI, A.; SCHOONHOVEN, A.V. Mites and insect pests of cassava. Annual Review of Entomology, v.23, p.39-67, 1978.

BELLOTTI, A.C.; SMITH, L.; LAPOINTE, S.L. Recent Advances in Cassava Pest Management. Annual Review of Entomology, v.44, n. 1, p.343-370, 1999.

BELLOTTI, A.C.; KAWANO, K. Breeding approaches in cassava. In: MAXWELL, F.G.; JENNINGS, P.R. (Eds). Breeding plants resistant to insects. New York: John Wiley \& Sons Press. v.1, 1980. 680p.

BOZA, J.A.; WADDILL, V.H. A cassava shoot fly, Neosilva perezi Romero and Ruppel: notes on biology and effect on cassava yield. Proceedings of the Tropical Region American Society for Horticultural Science, v.22, p.226-237, 1978.

BRINHOLI, O.; NAKAGAWA, J.; MARCONDES, D.A.S.; MACHADO, J.R. Estudo do comportamento de alguns "cultivares" de mandioca ao ataque da broca-dos-brotos (Silba pendula). Revista de Agricultura, v.49, p.181-183, 1974.

CAPINERA, J.L. (Ed). Encyclopedia of Entomology. Dordrecht: Kluwer Academic Publishers, 2004. 2580p.

CARROLL, L.E.; WHARTON, R.A. Morphology of the immature stages of Anastrepha ludens (Diptera: Tephritidae). Annals of the Entomological Society of America, v.82, p.201-214, 1989.

DE CONTI, E.; DEL VECCHIO, M.C.; DE SOUZA, H.M.L.; MORGANTE, J.S.; PIEDRABUENA, A.E. Allozimic variability in natural Silba spp. populations (Diptera: Lonchaeidae). Revista Brasileira de Genética, v.7, n.3, p.419-432, 1984.

FARIAS, A.R.N.; MATTOS, P.L.P.; FERREIRA, J.R. Artrópodes praga associados à cultura da mandioca em Presidente Tancredo Neves, BA. Revista Raízes e Amidos Tropicais, v.3, p. 1-5, 2007.

FHIA. FUNDACIÓN HONDURENA DE INVESTIGACÓN AGRÍCOLA (Ed). Informe técnico: Programa de Diversificación. Honduras: FHIA Press, 2003. 76p.

GISLOTI, L.; PRADO, A.P. Cassava shoot infestation by larvae of Neosilba perezi (Romero \& Ruppell) (Diptera: Lonchaeidae) in São Paulo State, Brazil. Neotropical Entomology, v.40, n.3, p.312-315, 2011.

GRANER, E.A. Tratamento de mandioca pela colchicina: II. Formas polipóides obtidas. Bragantia, v.2, n.2, p.23-54, 1942.

HOGUE, C.L. (Ed). Latin American insects and entomology. Berkeley: University California Press, 1993. 594p.
JALDO, H.E.; GRAMAJO, M.C.; WILLINK, E. Mass rearing of Anastrepha fraterculus (Diptera: Tephritidae): a preliminary strategy. The Florida Entomologist, v.84, p.716-718, 2001.

KING, A.B.S.; SAUNDERS, J.L. (Eds). The invertebrate pests of annual food crops in Central America. London: Overseas Development Administration, 1984. 166p.

KRIVOSHEINA, M.G. The structure and topography of spiracles in larvae of the lower Brachycera (Diptera, Brachycera, Orthorrhapha) in relation to their mode of life. Entomological Review, v.85, n.9, p. $1100-1126,2005$.

LAWRENCE, P.O. Immature stages of the Caribbean fruit fly Anastrepha suspensa. Florida Entomologist, v.62, p.214-219, 1979.

LORENZI, J.O.; DIAS, C.A.C. (Ed). Cultura da mandioca. Campinas: Coordenadoria de Assistência Técnica Integral, 1993. 41 p.

LOURENÇÃO, A.L.; LORENZI, L.O.; AMBROSANO, G.M.B. Comportamento de clones mandioca em relação à infestação por Neosilba perezi (Romero \& Ruppell) (Diptera: Lonchaeidae). Scientia Agricola, v.53, n.2/3, p.304-308, 1996.

MAGALHÃES, B.P. (Ed). Insetos e acaros nocivos a mandioca na Amazônia. Belém: Boletim de Pesquisa - Embrapa Amazonia Oriental, $1981.35 p$

MARCONDES, C.B. Morfometria e DNA mitocondrial de populações sul americanas de Lutzomyia (Nyssomyia) intermedia (Lutz \& Neiva, 1912) (Diptera, Psychodidae, Phlebotominae). Revista da Sociedade Brasileira de Medicina Tropical, v.30, n.6, p.533-534, 1997.

MCALPINE, J.F. A new species of Dasiops (Diptera:Lonchaeidae) injurious to apricots. The Cannadian Entomologist, v.93, p.539544, 1961.

MCALPINE, J.F.; STEYSKAL, G.C. A revision of Neosilba McAlpine with a key to the world genera of Lonchaeidae (Diptera). The Canadian Entomologist, v. 1 14, n.2, p.105-138, 1982.

MCALPINE, J.F. Lonchaeidae. In: MCALPINE, J.F.; PETERSON, B.V.; SHEWELL, G.E.; TESKEY, H.J.; VOCKEROTH, J.R.; WOOD, D.M. Manual of Nearctic Diptera. Quebec: Research Branch, Agriculture Canada, 1987. 1332p. Monograph 28.

MCALPINE, J.F. Morphology and terminology - adults. In: MCALPINE, J.F.; PETERSON, B.V.; SHEWELL, G.E.; TESKEY, H.J.; VOCKEROTH, J.R.; WOOD, D.M. (Eds). Manual of Nearctic Diptera. Ottawa: Research Branch, Agriculture Canada, 1989. p.791-796.

OLIVEIRA, F.N.S. (Ed). Caracterização botânico-agronômica de cultivares de mandioca (Manihot esculenta Crantz) em Porto Velho, Rondônia. Porto Velho: EMBRAPA-UEPAE, 1987. 14p. 
OLIVEIRA, A.M.G.; NORONHA, A.C.; GOMES, H.S.; SILVA, J.; FERREIRA FILHO, J.R.; DINIZ, M.S.; DITA RODRIGUES, M.A.; SANTOS, V.S.; OLIVEIRA, J.L. Elaboração de sistemas de produção de mandioca para o Extremo Sul da Bahia. In: SANTOS, M.G.B. (Ed). Artigos técnicos divulgados na mídia: coletânea 2007. Brasília: Embrapa Recursos Genéticos e Biotecnologia Boletim Agropecuário: artigos técnicos, 2007. 3p.

PENA J.E.; WADDILL, V. Pests of cassava in South Florida. The Florida Entomologist, v.65, n.1, p.143-149, 1982.

REINECKE, J.P. Nutrition: Artificial diets. In: KERKUT, G.A.; GILBERT, L. (Eds). Comprehensive Insect Physiology, Biochemistry and Pharmacology. New York: Pergamon Press, 1985. p.391-419.

SAUNDERS J.L., СОTO D.T.; KING A.B.S. (Eds). Plagas invertebradas de cultivos anuales alimenticios en América Central. Turrialba: CATIE, 1998. 305p. Serie Técnica/Manual Técnico n.29.

SELIVON, D.; PERONDINI, A.L. P. Description of Anastrepha sororcula and $A$. serpentina (Diptera: Tephritidae) eggs. The Florida Entomologist, v.82, n.2, p.347-353, 1999.

SILVA, A.B.; MAGALHAES, B. P.; COSTA, M.S. (Eds). Insetos $e$ ácaros nocivos a mandioca na Amazônia. Belém: EMBRAPACPATU, 1981. 35p.
SOBRINHO, R.B.; CÁCERES, C.; ISLAM, A.; WORNOAYPORN, V.; ENKERLIN, W. Improving mass rearing technology for south american frui fly Diptera:Tephritidae). Revista Caatinga, v.19, n.3, p.310-316, 2006.

SOUZA, S.P.; MATIAS, E.C.; LOPES, E.B. (Eds). Cultura da mandioca. João Pessoa: Emater-PB, 1982. 33p.

SOUZA, J.C.; REIS, P.R. (Eds). Cassava pests in Minas Gerais, Brazil (Pseudococcus sp, Coelosternus rugicollis, Anastrepha sp, Neosilba perezi, Vatiga illudens, Erinnyis ello ello). Belo Horizonte: BINAGRI, Empresa de Pesquisa Agropecuaria de Minas Gerais, 1986. 32p.

STECK, G.J.; WHARTON R.A. Description of immature stages of Anastrepha interrupta, A. limae, A. grandis (Diptera: Tephritidae). Annals of the Entomological Society of America, v.81, p.994$1003,1988$.

ZIKAN, W. A mosquinha dos mandiocais, Lonchaea pendula, Bezzi, 1919. Chácaras e Quintais, v.70, p.489-492, 1944.

ZUCOLOTO, F.S.; PUSCHE, S.; MESSAGE, C.M. Valor nutritivo de dietas artificiais para Anastrepha obliqua (Diptera: Tephritidae). Boletim de Zoologia da Universidade de São Paulo, v.4, p.75-80, 1979.

WADDILL, V.H. Biology and economic importance of a cassava shoot fly, Neosilba perezi (Romero and Ruppel). In: BELOTTI, A.; LOZANO, J.C. (Eds). Cassava Protection Workshop. Cali: Centro Internacional de Agricultura Tropical, p.209-214, 1978. 